\title{
Narrative Review for Exploring Barriers to Readi- ness of Electronic Health Record Implementation in Primary Health Care
}

\author{
Sandra Hakiem Afrizal ${ }^{1}$, Achmad Nizar Hidayanto ${ }^{2}$, Putu Wuri Handayani ${ }^{2}$, Meiwita Budiharsana ${ }^{1}$, \\ Tris Eryando ${ }^{1}$ \\ ${ }^{1}$ Faculty of Public Health, Universitas Indonesia, Jawa Barat, Indonesia \\ ${ }^{2}$ Faculty of Computer Science, Universitas Indonesia, Jawa Barat, Indonesia
}

Objectives: The aim of this study is to explore the enabling factors associated with readiness in Electronic Health Record (EHR) implementation and to identify the barriers related to readiness regarding the situation of primary health cares in developed and developing countries. Methods: A narrative review of open-source literature was conducted using the ProQuest, ScienceDirect, MEDLINE, and PMC databases to identify the enabling factors and barriers to EHR readiness. The keywords applied were 'electronic health record', 'readiness', 'primary health care', and 'primary care'. Results: Some barriers were found that may affect readiness, specifically individual barriers and organizational barriers. In developing countries, organizational barriers such as a lack of skilled manpower, insufficient senior management, and a lack of interaction among team members were the common barriers, while in developed countries individual barriers such as unfamiliarity with new systems and a lack of time to use computers were frequently found as barriers to readiness. Conclusions: This study summarized the enabling factors and barriers with regard to EHR readiness in developed and developing countries.

Keywords: Electronic Health Records, Barrier, Readiness, Primary Health Care, EHR Adoption

Submitted: February 24, 2019

Revised: 1st, June 15, 2019; 2nd, July 13, 2019

Accepted: July 16, 2019

\section{Corresponding Author}

Sandra Hakiem Afrizal

Faculty of Public Health, Universitas Indonesia, Depok Campus, Jawa Barat 16424, Indonesia. Tel: +62-217864975, E-mail: sandra@ uinjkt.ac.id (https://orcid.org/0000-0001-6551-6946)

This is an Open Access article distributed under the terms of the Creative Commons Attribution Non-Commercial License (http://creativecommons.org/licenses/by$\mathrm{nc} / 4.0 /$ ) which permits unrestricted non-commercial use, distribution, and reproduction in any medium, provided the original work is properly cited.

(c) 2019 The Korean Society of Medical Informatics

\section{Introduction}

The declaration of 'Health for All by the Year 2000' by the World Health Organization (WHO) emphasized the need for better healthcare services not only at the hospital level, but also for primary health care (PHC) and community health services [1]. Hospitals as secondary care facilities in developed and developing countries have already adopted Electronic Health Records (EHR) and have done so longer than primary care organizations [2]. Previous research found that electronic health services, such as the use of the EHR system, improves accessibility, coordinates patient care, improves management, and increases patient safety and the quality of treatments $[3,4]$.

Although EHR implementation has already been established in some developing countries, the continuity and 
sustainability of EHR adoption is either low or underutilized [2]. The cost of shifting to electronic documentation coupled with inadequate healthcare funding, large populations and remote communities, limited availability of technology, a lack of technical expertise and low computer skills of staff members, and a lack of facilities are the major issues preventing the adopting of electronic health systems in developing countries. Hence, the WHO recommended a guideline for EHR implementation for developing countries [5].

To date, many studies have been conducted to review the adoption of EHR for primary care in developed countries such as Canada, the United States, and the United Kingdom [6]. The success factors of electronic records are related to individual readiness factors such as knowledge, attitudes, and computer-related skills and are also associated with preparedness evaluations of the components of an organization before the application $[7,8]$. Thus, the readiness of healthcare staff or individuals as well as the organization should be assessed prior to system implementation because any of these factors may not be fully prepared to accept the change and the new system [9].

Given that the number of reviews of EHR implementation experiences in the PHCs of developing countries remains very limited, a current review of EHR adoption during the setup of PHCs in developed and developing countries is timely and crucial due to the fundamental function of PHCs as the first level of care and as a source of coordinated care for people in the community. Furthermore, preparation strategies, such as recognizing the enabling factors and barriers to readiness, should be assessed before adopting the system because they are related to the continuity of health information technology adoption in low-resource settings, such as a PHC, where reliable data is also needed to support public health and local supporting organizations [10]. In addition, a review of the enabling factors and barriers related to EHR implementation in PHCs in both developed and developing countries has not been done before to the best of the authors' knowledge.

To address this gap, the authors conducted a narrative review of the literature with respect to barriers to readiness for EHR adoption in PHCs. The introduction to the EHR development process included the recognition that the enabling factors and barriers to readiness should necessarily include local governments, healthcare providers, and administrators before the implementation process. This is essential to highlight the need for preparing a review of the readiness to adopt the EHR application based on the type of country. For analytical purposes, the authors classified the places of research based on the World Economic Situation and Prospects (WESP) approach, which classifies all countries of the world into categories: developed and developing countries [11]. The objective of this study was to explore the enabling factors associated with the readiness for EHR implementation in primary care. A second objective is to recognize barriers to readiness in developed and developing countries.

\section{Literature Review}

\section{Health Record Systems in Primary Health Care}

The WHO has established standards for health records in primary healthcare $[12,13]$. The types of standards typically assessed include: (1) basic patient demographic identification and clinical information at the first visit, including previous medical history and allergies, family/social history; (2) ongoing or continuation of the record, including previous or the updating of any problem and medication lists, and organising progress notes, lab and consultation reports, and other documentation within the record; (3) chief complaint, symptoms and signs, a clinically appropriate treatment plan, follow-up plan, provider signature, and next visit date; (4)

Table 1. Differences in EMR, EHR and PHR

\begin{tabular}{lllc}
\hline \multicolumn{1}{c}{ Indicator } & \multicolumn{1}{c}{ EMR } & EHR & PHR \\
\hline Content & Medical information from internal & Medical information from clinicians & Medical information from clinicians \\
& clinical works & and lab & and lab \\
Accessibility & Limited access (internal & Interoperable (inter-organizational & Managed personally \\
& organization) & system) & (inter-organizational system) \\
Source of data & Clinician from single provider & Clinician or analyst from multiple & Clinician or analyst from multiple \\
& & providers (inter-facility) & providers (inter-facility) \\
Function & Internal medical record & Information exchange between & Personal medical information \\
& & organizations & \\
\hline
\end{tabular}

EMR: Electronic Medical Record, EHR: Electronic Health Record, PHR: Personalised Health Record. 
plan for preventive care, including immunisations and patient education (e.g., drug assessment and counselling) and documentation of advance instructions; and (5) plan for coordinate care with other providers, such as follow-up on referrals to a hospital and the initialling of lab findings and reports from expert consultants.

\section{Electronic Record for Medical Documentation in Primary Health Care}

Based on research by Rodrigues et al. [14], the use of electronic reports in a small healthcare facility such as a PHC allows physicians to access the records of patients in a rapid and simple way. There are three forms of electronic records: the Electronic Medical Record (EMR), the EHR, and the Personalised Health Record (PHR) [5,15] (Table 1).

The WHO definition of an EMR is an electronic version of a medical record in healthcare facilities such as hospitals and PHCs. It contains medical information from clinical works for diagnosis and/or treatment. The EHR is compiled as a source of clinical data in a healthcare facility. It includes information from all clinicians or laboratories which are involved in the care or diagnosis of a patient. Other providers are able to access the patient's information and provide care for the patient using the health record. The PHR is an EHR managed by patients. It covers health information from many sources, including clinicians, laboratories, or from the patient and can be managed as confidential by the patient (Figure 1).

As the first level of the provision of healthcare, PHCs play an important role as a hub of coordination to provide a basic level of care and to help people to find a specialised service in other facilities by means of coordination and collabora-

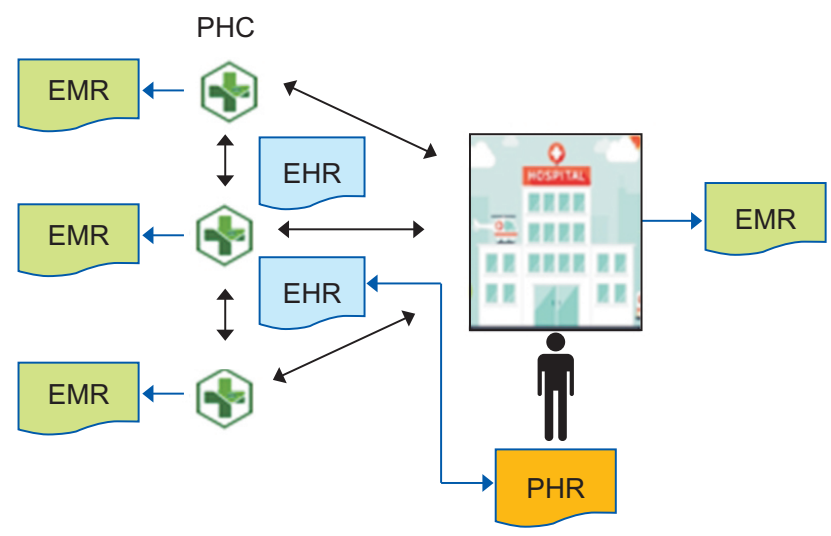

Figure 1. Form of electronic documentation to record the medical data of a patient. PHC: primary health care, EMR: Electronic Medical Record, EHR: Electronic Health Record, PHR: Personalised Health Record. tion with other types of organizations, such as hospitals [16]. Information exchanges between organizations are necessarily managed carefully to maintain the quality of care. The use of information technology may be beneficial for the coordination system between the PHC team and the staffs of other facilities [17].

\section{Electronic Health Record Adoption}

The computer-based patient record (CPR) as the first type of electronic record was introduced in the 1990s in the United States [5]. By the year 2000, the WHO stipulated the implementation of EHR for better healthcare services from the primary healthcare level to the secondary level of care (hospitals) and other healthcare services or organizations. The EHR was initially used to store data regarding claims of insurance, for document capturing by image scanning, and laboratory results and clinical use factors as patient documentation either in an outpatient clinic or an inpatient clinic at hospitals in developed countries [18].

The capability of the EHR system has increased significantly with several new functionalities in primary care using

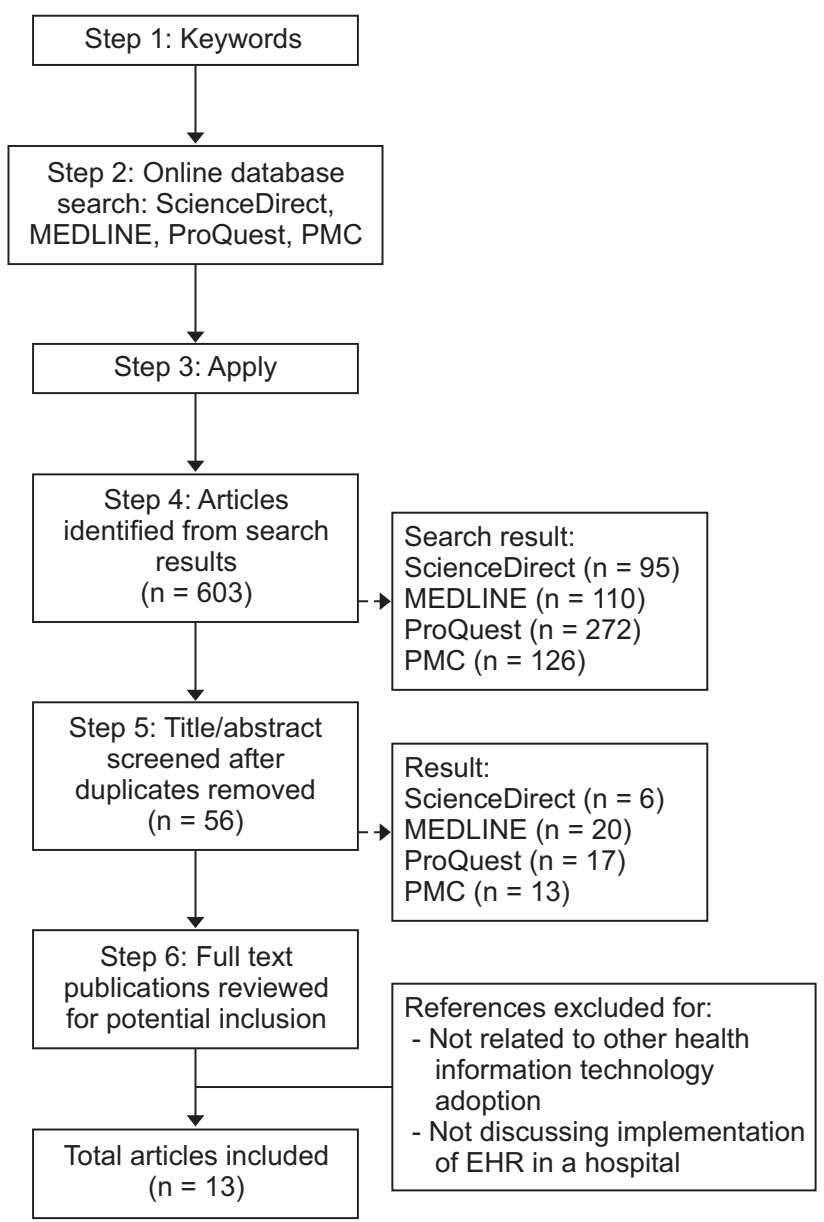

Figure 2. Literature search steps. EHR: Electronic Health Record. 
patient-clinician interactions in virtual consultations and telemedicine. The documentation of clinical works by multiple organizations which use EHR systems starts with primary care physicians, experts (specialty and subspecialty) at hospitals, private laboratories, insurance companies and the patients [19]. The adoption of an EHR system by a healthcare facility should be done to increase healthcare efficiency, reduce the unnecessary duplication of services, and to improve confidentiality of the data as well as the quality of care among the population [5].

\section{Methods}

We conducted a literature review to identify relevant papers published between 2006 and 2018 by applying the keywords 'electronic health record' and 'readiness' or 'barrier' or 'enabling factors' and 'primary health care' or 'primary care'. The inclusion criterion was that the articles should be published in English.

Figure 2 describes the essential steps of the literature search process. Based on earlier work [20], the search strategies included Step 1, which involved finding the keywords to search for the articles. Step 2 targeted the open-source databases. The authors chose the MEDLINE/PubMed, ScienceDirect, ProQuest, and PMC databases as they provide medical databases. Step 3 applied the terms or keywords. Step 4 and Step 5 selected the articles and removed any duplicates, respectively. Step 6 was a review of the full text and excluded an article if it was not related to the aim of the study.

\section{Selection Criteria}

The studies involved in this review met the following criteria.

\section{1) Empirical phase}

The studies had empirical phase in their study design, such as a qualitative, quantitative, or a mixed method. A clear data collection process was stated along with objectives of the research and a clear description of the measurement tools.

\section{2) Enabling factors related to readiness}

Enabling factors related to readiness are the critical success aspects in the implementation of EHR system. Based on previous studies, the enabling factors of readiness involved two major factors [21,22]:

- Individual readiness: This factor is divided into individual psychological factors and individual structural factors. Psychological factors consist of elements which may reflect individual beliefs regarding a change to a new technology, identifying problems, and the level of agreement with the changes. Structural factors are related to the ability of an individual to adapt to the new technology.

- Organizational readiness: This involves organizational psychological and organizational structural factors. The psychological aspect is linked to the beliefs of organizational members regarding their commitment and efficacy, while the structural aspect is associated with human and material resources, policies, and communication networks.

The selected articles should have clear methods and the result should show the influence of the enabling factors and barriers related to readiness to use a new technology.

\section{3) Barriers to readiness in EHR implementation}

It is necessary to identify and eliminate these barriers before designing and implementing a system, as barriers are important effects that influence readiness [23]. Barriers in this case refer to obstacles which potentially prevent the implementation of electronic records. In each country, the problems hindering the implementation of electronic records would be very different, especially between developed and developing countries. Despite the potential benefits of adopting the EHR system, the progress of EHR adoption in developing countries is much slower compared to that in developed countries [24]. Based on research by Ajami et al. [23], the barriers preventing the adopting of health information technology are classified into five aspects: (1) organizational factors such as a lack of efficient planning, a lack of skilled manpower, and limitations related to training courses; (2) individual factors such as a lack of knowledge, unfamiliarity, user resistance, a lack of willingness to learn new skills, and limited awareness; (3) financial barriers such as a shortage of funds for the design, a lack of strategic planning, and a lack of incentives; (4) ethical-legal barriers including unauthorized access to patient information, computer system security, the security of the health data exchange, and a lack of an appropriate legal framework or policy; and (5) technical barriers such as a lack of a national health information network,

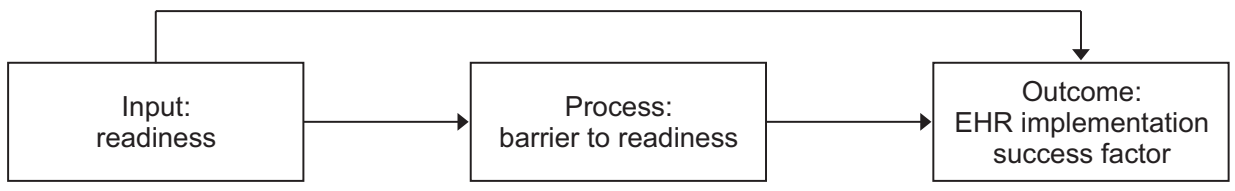

Figure 3. Theoretical framework of Electronic Health Record (EHR) implementation success factors. 
Table 2. Empirical phase of the review

\begin{tabular}{|c|c|c|c|c|c|}
\hline \multirow{2}{*}{ Study, year } & \multirow{2}{*}{ Country } & \multirow{2}{*}{ Type of study } & \multicolumn{2}{|c|}{ Enabling factors } & \multirow{2}{*}{ Barriers } \\
\hline & & & Individual readiness & Organizational readiness & \\
\hline $\begin{array}{l}\text { Mannan et al. } \\
\text { [26], } 2006\end{array}$ & UK & $\begin{array}{l}\text { Qualitative } \\
\text { study }\end{array}$ & $\begin{array}{l}\text { Willingness, time to } \\
\text { adaptation }\end{array}$ & Training & $\begin{array}{l}\text { Mistrust of technology, } \\
\text { negative perceptions }\end{array}$ \\
\hline $\begin{array}{l}\text { Shea et al. [27], } \\
2014\end{array}$ & USA & $\begin{array}{l}\text { Quantitative } \\
\text { study }\end{array}$ & $\begin{array}{l}\text { Willingness, awareness, } \\
\text { perceptions of benefits }\end{array}$ & $\begin{array}{l}\text { Review appropriateness } \\
\text { and attention, incentives }\end{array}$ & Unwilling to change \\
\hline $\begin{array}{l}\text { Pandhi et al. } \\
\text { [28], } 2014\end{array}$ & USA & $\begin{array}{l}\text { Qualitative } \\
\text { study }\end{array}$ & Communication skills & $\begin{array}{l}\text { Team work, interaction, } \\
\text { budget planning }\end{array}$ & $\begin{array}{l}\text { Workload, tension, stressor, } \\
\text { non-standardized } \\
\text { documentation, software } \\
\text { problems }\end{array}$ \\
\hline $\begin{array}{l}\text { Mason et al. [29], } \\
2017\end{array}$ & USA & $\begin{array}{l}\text { Qualitative } \\
\text { study }\end{array}$ & $\begin{array}{l}\text { Communication, } \\
\text { attitudes }\end{array}$ & $\begin{array}{l}\text { Financial support, } \\
\text { training }\end{array}$ & $\begin{array}{l}\text { Resistance, lack of finance } \\
\text { support, non-standardized } \\
\text { documentation, lack of } \\
\text { knowledge }\end{array}$ \\
\hline $\begin{array}{l}\text { Saleh et al. [30], } \\
2016\end{array}$ & Lebanon & $\begin{array}{l}\text { Quantitative } \\
\text { study }\end{array}$ & $\begin{array}{l}\text { Knowledge, time on the } \\
\text { computer }\end{array}$ & Access to information & Computer literacy \\
\hline $\begin{array}{l}\text { Shin and Sharac } \\
\text { [31], } 2013\end{array}$ & USA & $\begin{array}{l}\text { Quantitative } \\
\text { study }\end{array}$ & - & $\begin{array}{l}\text { Assistance, training, } \\
\text { incentives, time to adapt }\end{array}$ & Complex work flow \\
\hline $\begin{array}{l}\text { Melas et al. [32], } \\
2013\end{array}$ & Greece & $\begin{array}{l}\text { Quantitative } \\
\text { study }\end{array}$ & $\begin{array}{l}\text { Knowledge, ICT } \\
\text { performance, attitudes, } \\
\text { innovation, professional } \\
\text { status, culture, } \\
\text { demography, awareness }\end{array}$ & Assistance & $\begin{array}{l}\text { Computer literacy, } \\
\text { resistance }\end{array}$ \\
\hline $\begin{array}{l}\text { Fuji et al. [33], } \\
2008\end{array}$ & USA & $\begin{array}{l}\text { Quantitative } \\
\text { study }\end{array}$ & $\begin{array}{l}\text { Awareness, } \\
\text { communication, } \\
\text { perception, optimism, } \\
\text { gender, professional } \\
\text { status }\end{array}$ & $\begin{array}{l}\text { Integration, qualified } \\
\text { organization } \\
\text { (accreditation status) }\end{array}$ & $\begin{array}{l}\text { Unfamiliarity, lack } \\
\text { of knowledge not } \\
\text { interoperable system, lack } \\
\text { of policy }\end{array}$ \\
\hline $\begin{array}{l}\text { Vydra et al. [34], } \\
2015\end{array}$ & USA & $\begin{array}{l}\text { Qualitative } \\
\text { study } \\
\text { (FGD) }\end{array}$ & $\begin{array}{l}\text { Time of computer use, } \\
\text { positive attitude, } \\
\text { knowledge, professional } \\
\text { status, demography (age) }\end{array}$ & $\begin{array}{l}\text { Financial support } \\
\text { (incentives), integrated } \\
\text { system, quality of EHR }\end{array}$ & $\begin{array}{l}\text { Lack of reimbursement for } \\
\text { time spent, workload }\end{array}$ \\
\hline $\begin{array}{l}\text { Ayatollahi et al. } \\
\text { [35], } 2015\end{array}$ & Iran & $\begin{array}{l}\text { Quantitative } \\
\text { study }\end{array}$ & - & $\begin{array}{l}\text { Training, technical, } \\
\text { financial, ethical-legal } \\
\text { issues }\end{array}$ & $\begin{array}{l}\text { Complexity of activities } \\
\text { (workload) insufficient } \\
\text { senior support, technical } \\
\text { barriers, lack of security }\end{array}$ \\
\hline $\begin{array}{l}\text { Papoutsi et al. } \\
\text { [36], } 2015\end{array}$ & UK & $\begin{array}{l}\text { Mixed- } \\
\text { method }\end{array}$ & Willingness & Security/privacy, policy & $\begin{array}{l}\text { Unauthorized access, } \\
\text { inaccuracy }\end{array}$ \\
\hline $\begin{array}{l}\text { Darko-Yawson } \\
\text { and Ellingsen } \\
\text { [37], } 2016\end{array}$ & Ghana & $\begin{array}{l}\text { Qualitative } \\
\text { study }\end{array}$ & Attitudes, perception & $\begin{array}{l}\text { Collaborative work, } \\
\text { formulised role/policy, } \\
\text { IT human resources }\end{array}$ & $\begin{array}{l}\text { Resistance to change, poor } \\
\text { participation, inadequate } \\
\text { staff, non-standardized } \\
\text { system }\end{array}$ \\
\hline $\begin{array}{l}\text { Terry et al. [38], } \\
2008\end{array}$ & UK & $\begin{array}{l}\text { Qualitative } \\
\text { study }\end{array}$ & $\begin{array}{l}\text { Commitment, willingness, } \\
\text { knowledge }\end{array}$ & $\begin{array}{l}\text { Training, time to adapt to } \\
\text { the new system }\end{array}$ & Unfamiliarity \\
\hline
\end{tabular}

FDG: Focus Group Discussion, EHR: Electronic Health Record. 
a lack of an efficient hospital information system, a lack of the proper equipment and hardware necessary to implement the EHR system and programming and software according to the needs, a lack of appropriate infrastructure for the integration of EHR, a lack of a national standard terminology for the EHR system, a lack of national standards for data exchange, and incompatibility among information systems in terms of structure, content, and functions.

Based on research by Abdulrahman and Subramanian [25], a lack of efficient planning, a lack of skilled manpower, and limitations related to training courses are categorised as management barriers. In this review, we merged the management barriers, technical barriers, ethical-legal barriers, and financial barriers into the organizational factor category. Previous work concluded that readiness and barriers to readiness are related to the adoption rate of technology [2]. The sustainability and the success factors of EHR implementation are described in Figure 3.

Table 3. Enabling factors of readiness in the implementation of EHR

\begin{tabular}{|c|c|c|c|c|}
\hline IT readiness & Enabling factors & $\begin{array}{c}\text { Articles from } \\
\text { developed countries }\end{array}$ & $\begin{array}{c}\text { Articles from } \\
\text { developing countries }\end{array}$ & Sources \\
\hline \multirow{14}{*}{$\begin{array}{l}\text { Individual } \\
\text { readiness }\end{array}$} & Psychological factors & & & \\
\hline & Willingness & 4 & - & {$[26][27][36][38]$} \\
\hline & Awareness & 3 & - & {$[27][32][33]$} \\
\hline & Optimism & 1 & - & {$[33]$} \\
\hline & Innovative culture & 1 & - & [33] \\
\hline & Positive attitude & 3 & 1 & {$[29][32][34][37]$} \\
\hline & Perception of benefits & 1 & 1 & {$[27][37]$} \\
\hline & Structural aspects & & & \\
\hline & Demographic factor & 3 & - & {$[32][33][34]$} \\
\hline & Communication skills & 2 & - & {$[28][29]$} \\
\hline & Knowledge & 3 & 1 & {$[30][32][34][38]$} \\
\hline & Professional status & 3 & - & {$[32][33][34]$} \\
\hline & Computer skills & 1 & - & {$[32]$} \\
\hline & Duration of computer use & 2 & 1 & {$[26][30][34]$} \\
\hline \multirow{18}{*}{$\begin{array}{l}\text { Organizational } \\
\text { readiness }\end{array}$} & Psychological factors & & & \\
\hline & Incentives & 4 & - & {$[27][29][31][34]$} \\
\hline & Teamwork & 1 & 1 & {$[37][28]$} \\
\hline & Training & 4 & 1 & {$[26][29][31][35][38]$} \\
\hline & Assistance & 2 & - & {$[31][32]$} \\
\hline & Monitoring & 1 & - & [27] \\
\hline & Budget planning & 1 & 1 & {$[28][35]$} \\
\hline & Access to information & - & 1 & [30] \\
\hline & Accreditation status (qualified organization) & 1 & - & [33] \\
\hline & Collaborative work & - & 1 & {$[37]$} \\
\hline & Adaptation to the new system & 2 & - & {$[31][38]$} \\
\hline & Structural factors & & & \\
\hline & IT infrastructure & 1 & 1 & {$[32][35]$} \\
\hline & IT human resources & - & 1 & {$[37]$} \\
\hline & Security/privacy & 1 & - & [36] \\
\hline & Policy & 1 & 1 & {$[37][36]$} \\
\hline & Ethical-legal & - & 1 & [35] \\
\hline & System integration (quality of EHR) & 2 & - & [33][34] \\
\hline
\end{tabular}




\section{Results}

\section{Empirical Phase}

From a total of 13 articles that were reviewed, it was found that 6 used quantitative studies (Table 2). Most of the methods used involved a cross-sectional study design, and the subjects of the research were mostly medical staff at healthcare facilities. Among the articles, 6 citations used qualitative methods, while 1 other citation used a mixed method. The research of 10 articles (77\%) was conducted in developed countries such as the United Kingdom, the United States and Greece, while the other 3 articles (23\%) were from developing countries such as Lebanon, Iran, and Ghana.

\section{Enabling Factor of Readiness}

All of the enabling factors that influence readiness are discussed in the following articles (Table 3). Based on the literature review, the psychological factors of individual readiness in developed countries as enabling factors of readiness were willingness ( 4 articles), awareness ( 3 articles), a positive attitude (4 articles), optimism (1 article), an innovative culture (1 article) and perception of benefits ( 1 article). In developing countries, a positive attitude ( 1 article) and the perception of benefits ( 1 article) were found as the psychological aspects of individual factors. The structural factors of individual readiness in developed countries were related to demographic factors ( 3 articles), knowledge ( 3 articles), communication skills (2 articles), professional status (3 articles), computer skills ( 1 article) and the intensity of computer use (2 articles). However, in developing countries, knowledge and the duration of computer use were related to the structural factors of individual readiness.
Organizational readiness aspects also play an important role in EHR implementation [9]. Based on research by Timmings et al. [22], there are two enabling factors of organizational readiness: psychological factors and structural factors. Based on the review, in developed countries it was apparent that incentives and training were the common psychological factors mentioned in the articles ( 4 articles). Adaptation to a new system, assistance, teamwork, a qualified organization or accreditation status, monitoring and budget planning were also found to be psychological factors of organizations in developed countries. However, in developing countries, teamwork, training, the budget planning, access to information and collaborative work with other institutions were found to be the structural factors of organizations.

The second aspect of organizational readiness is the structural factor. In developed countries, the IT infrastructure, security and privacy, EHR policies and system integration were found to be the structural factors of organizational readiness. In developing countries, the IT infrastructure, IT human resources, and policy and ethical-legal issues were found to be the structural factors of readiness. Based on these findings, the authors developed a conceptual framework to briefly explain the readiness of EHR implementation (Figure 4).

\section{Barriers to Readiness in Adopting EHR}

Barriers to readiness were identified in the 13 articles displayed in Table 4. The authors subsequently differentiated potential barriers between developed and developing countries.

From Table 4, there were 5 studies which mentioned individual barriers in developed countries. Commonly, it was

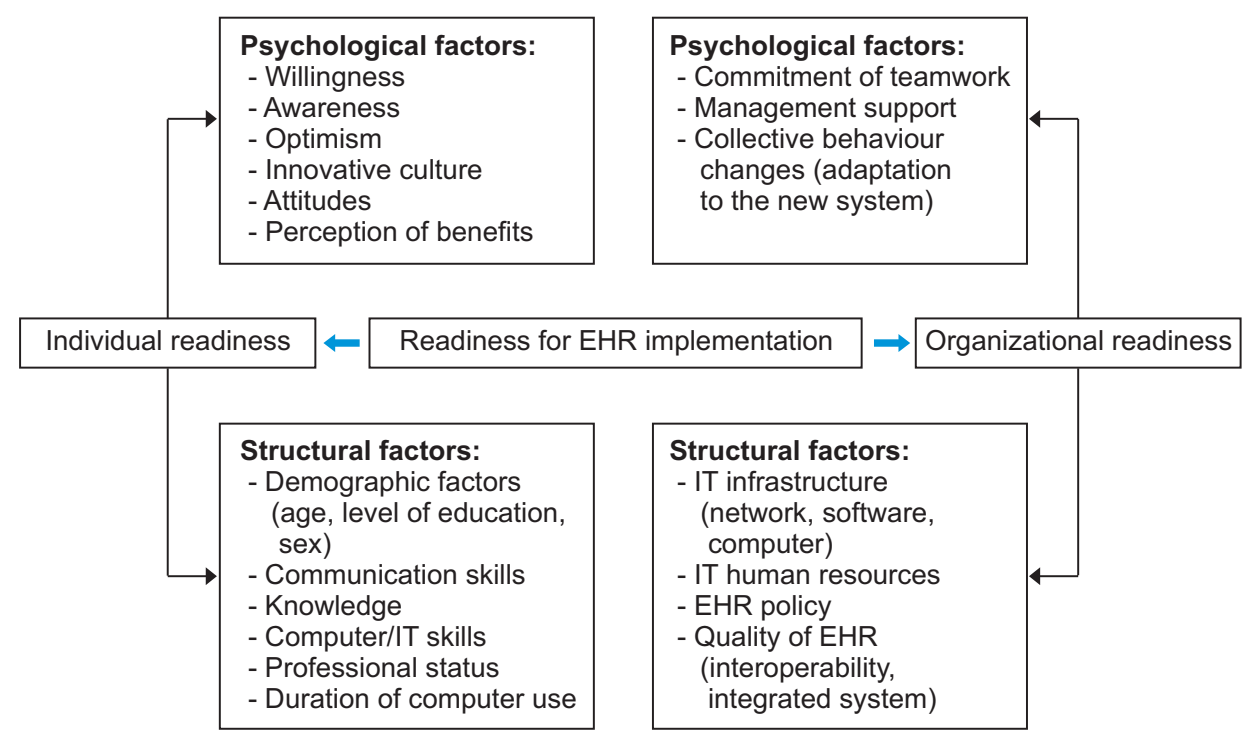

Figure 4. Conceptual framework of readiness in adopting Electronic Health Record (EHR). 
Table 4. Potential barriers in developed and developing countries

\begin{tabular}{|c|c|c|c|c|}
\hline Barriers & Indicator & $\begin{array}{c}\text { Articles from } \\
\text { developed countries }\end{array}$ & $\begin{array}{c}\text { Articles from } \\
\text { developing countries }\end{array}$ & Sources \\
\hline \multirow[t]{8}{*}{ Individual factor } & Unfamiliarity & 3 & - & {$[28][33][38]$} \\
\hline & User resistance (limited awareness) & 2 & 1 & {$[29][32][37]$} \\
\hline & Mistrust and fear & 1 & - & {$[26]$} \\
\hline & Lack of time to use the computer & 3 & - & {$[28][30][32]$} \\
\hline & High workload & 2 & 1 & {$[28][34][35]$} \\
\hline & Lack of knowledge and competency & 2 & 1 & {$[29][33][35]$} \\
\hline & Unwilling to change & 1 & - & {$[27]$} \\
\hline & High stressor & 1 & - & {$[28]$} \\
\hline \multicolumn{5}{|l|}{ Organizational factor } \\
\hline \multirow[t]{4}{*}{$\begin{array}{l}\text { Management } \\
\text { barriers }\end{array}$} & $\begin{array}{l}\text { Lack of skilled manpower, insufficient } \\
\text { senior management }\end{array}$ & - & 2 & {$[35][37]$} \\
\hline & Limitation related to training courses & 2 & 1 & {$[28][29][35]$} \\
\hline & Lack of a strategic implementation plan & - & 1 & {$[35]$} \\
\hline & $\begin{array}{l}\text { Lack of ability for mutual relationships and } \\
\text { interaction among team members }\end{array}$ & - & 2 & {$[35][37]$} \\
\hline \multirow[t]{3}{*}{ Financial barriers } & Shortage of funds for hiring more staff & 1 & - & {$[28]$} \\
\hline & Lack of a budget planning & 1 & 1 & {$[29][35]$} \\
\hline & Lack of incentives & 2 & - & {$[29][34]$} \\
\hline \multirow{3}{*}{$\begin{array}{l}\text { Ethical-legal } \\
\text { barriers }\end{array}$} & Unauthorized access to patient information & 1 & 1 & {$[35][36]$} \\
\hline & Lack of computer system security \& privacy & 1 & 1 & {$[35][36]$} \\
\hline & Lack of an EHR policy & 1 & - & {$[33]$} \\
\hline \multirow[t]{5}{*}{ Technical barriers } & Lack of efficient health information systems & 1 & 1 & {$[29][35]$} \\
\hline & Inaccuracy & 1 & - & {$[36]$} \\
\hline & Lack of proper software & 1 & - & {$[28]$} \\
\hline & $\begin{array}{l}\text { Lack of a national standard terminology for } \\
\text { an EHR system }\end{array}$ & 3 & 1 & {$[29][33][37]$} \\
\hline & Complexity of the service & - & 1 & {$[35]$} \\
\hline
\end{tabular}

EHR: Electronic Health Record.

unfamiliarity with the new application, while in developing countries, user resistance, a lack of awareness and a high workload were found as common barriers. Based on these findings, management barriers such as a lack of skilled manpower, a lack of related training courses, a lack of a strategic implementation plan, and a lack of interaction among team members were frequently found in developing countries compared to developed countries. Certain articles from among the three articles pertaining to the developed countries also mentioned financial barriers such as a lack of incentives and a lack of budget funds for hiring more personnel.

As shown in Table 4, ethical-legal barriers such as a lack of authorised access, a lack of privacy and a lack of EHR policies were found in articles from both developed and developing countries. However, technical barriers in developed countries, such as a lack of terminology standards for EHR, inaccuracies in the guidelines, and software problems were found to exist commonly during the adoption.

\section{Discussion}

Health providers must create an EHR implementation roadmap, establish teamwork with the participation of end users, select and prepare leadership, provide user training to operate the system and also prepare support to maintain and 
promote the system [39].

Based on the current findings, the lack of familiarity with the new technology is a common barrier among healthcare staff which usually arises in developed countries [27,32,37]. This is likely because health information technology develops very quickly and new applications may be introduced without any prior exposure. The lack of training and experience with regard to new application-related issues may have contributed to the high degree of rejection among the medical staff in developed countries [28]. Other research showed that familiarity with the new technology may limit the ability of health care providers to support the use of the system and therefore may lead to lower adoption rates [34].

In developing countries, poor computer knowledge was a common barrier to EHR adoption readiness [35]. Previous studies have shown that healthcare professionals who have are computer literate and who frequently use computers in their workplaces were likely to be ready for EHR implementation [25,31]. Professional status has also been found to be an enabling factor of technology adoption among healthcare staff $[32,33]$. Nurses were found to be usually deficient in computer literacy among medical personnel; this may cause more computer nervousness, which can affect the acceptance of health information technology [40]. Thus, management support efforts such as providing training programmes and assistance should be continually made to enhance the skill of the medical staff in using computers to run the application [31].

As some of the organizational barriers, management constraints such as a high staff turnover and a lack of training in the healthcare facility may result in limited skilled manpower and insufficient senior managers [34,36]. Based on previous studies, training or courses for related technology are not only limited in developing countries but also in developed countries [28]. This may be caused by poor strategic planning before the adoption of the technology. Moreover, limited skilled manpower such as clinical and administrative staff at a PHC may result in stress and tension due to the high workload among the team [28]. Based on research by Weiner [41], a successful EHR implementation requires the establishment of a team that includes clinical staff members and administrative and information technology personnel to build mutual relationships in the organization [7].

As shown in Table 4, financial barriers were commonly found in developed countries and a lack of incentives was found to be the main problem. To reduce the barriers, management support is the enabling factor for readiness for the adoption of EHR. For instance, the government of the
United Station has integrated a new system referred to as 'Meaningful Use. The programme started providing incentive payments to professionals, hospitals, and Medicare (a health insurance organization) to promote the adoption and meaningful use of interoperable health information technology and qualified EHRs [18].

Furthermore, ethical-legal barriers such as a lack of computer system security, a lack of privacy as well as a lack of a policy were found in relation to EHR adoption in developed and developing countries [34,35]. Currently, EHR applications allow a clinical team (clinicians and nurses) to document healthcare delivery in acute care hospitals and to guide healthcare delivery by automated clinical decision making [5]. Previous research found that ethical issues were often faced by the team during EHR adoption due to a lack of coherency or inaccuracies in the clinical guidelines when set automatically by the EHR application with regard to the conditions of actual patients [35,41]. A lack of inter-professional communication, competency, too great a workload and personal distress may lead to ethical issues [42]. All medical professionals must be ready to face these challenges and identify the requirements of the laws of their countries, the organization policies, and the commitments of the profession before the system is implemented.

Technical barriers such as a lack of a terminology standard for the EHR system was frequently found in studies of developed countries [33]. Electronic health data records were frequently incomplete due to different terminology standards. Based on the experience of EHR adoption in developed countries, the exchange of electronic health data plays an important role in EHR implementation [29]. Thus, the EHR system must be more universal, must apply a standardized terminology or protocol, must improve accuracy and must be applicable at each level of care.

The review results have implications for regulators, healthcare organizations, and developers who are involved in the adoption of the EHR system to build a strategic plan for their organizations. Regulators may also use the results as evidence to measure readiness before adopting a new EHR application and to develop the current EHR.

In conclusion, readiness is important to enhance the possibility of the successful adoption of an EHR system in a healthcare facility. There are two enabling factors of readiness: individual readiness and organizational readiness. Both are influenced by psychological and structural aspects. However, during the adoption process, there are several problems that may prevent the individual from fully accepting a new system and thus reduce organizational 
readiness, and such a situation may hinder EHR implementation in the primary care facilities of both developed and developing countries. Individual barriers such as unfamiliarity, organizational and financial barriers such as a lack of incentives, ethical-legal barriers such as a lack of policies, and technical barriers such as a lack of a terminology standard for EHR were common problems related to the implementation of an EHR system in developed countries. For developing countries, the workload due to the complexity of the service, a lack of manpower, and poor teamwork were common problems which may cause the slow adoption of new health information technology such as EHR. This study has summarised the enabling factors and barriers with regard to EHR readiness in developed and developing countries. Future research should build upon the results presented here and focus on the development of EHR implementation in primary health care.

\section{Conflict of Interest}

No potential conflict of interest relevant to this article was reported.

\section{Acknowledgments}

The authors would like to thank the Ministry of Education (Kemendikbud) for providing the PhD Scholarship.

\section{ORCID}

Sandra Hakiem Afrizal (http://orcid.org/0000-0001-6551-6946) Achmad Nizar Hidayanto (http://orcid.org/0000-0002-5793-9460) Putu Wuri Handayani (http://orcid.org/0000-0001-5341-3800) Meiwita Budiharsana (http://orcid.org/0000-0002-0213-0605)

Tris Eryando (http://orcid.org/0000-0001-9053-3174)

\section{References}

1. World Health Organization. Global strategy for health for all by the year 2000. Geneva, Switzerland: World Health Organization; 1981.

2. Zayyad MA, Toycan M. Factors affecting sustainable adoption of e-health technology in developing countries: an exploratory survey of Nigerian hospitals from the perspective of healthcare professionals. PeerJ 2018;6:e4436.

3. Doubova SV, Perez-Cuevas R, Ortiz-Panozo E, Hernandez-Prado B. Evaluation of the quality of antenatal care using electronic health record information in family medicine clinics of Mexico City. BMC Pregnancy Childbirth 2014;14:168.

4. Johnson RJ. A comprehensive review of an electronic health record system soon to assume market ascendancy: EPIC. J Healthc Commun 2016;1(4):36.

5. World Health Organization. Electronic health records: manual for developing countries. Manila, Philippines: Regional Office for the Western Pacific, World Health Organization; 2006.

6. McGinn CA, Grenier S, Duplantie J, Shaw N, Sicotte C, Mathieu L, et al. Comparison of user groups' perspectives of barriers and facilitators to implementing electronic health records: a systematic review. BMC Med 2011;9:46.

7. Biruk S, Yilma T, Andualem M, Tilahun B. Health professionals' readiness to implement electronic medical record system at three hospitals in Ethiopia: a cross sectional study. BMC Med Inform Decis Mak 2014;14:115.

8. Li J, Land LP, Chattopadhyaya S. E-Health readiness framework from Electronic Health Records perspective. Int J Internet Enterp Manag 2010;6(4):035626.

9. Cherry B, Owen D, Bachetti B. Determining factors of organizational readiness for technology adoption in long-term care facilities. Lubbock (TX): The Garrison Institute on Aging, Texas Tech University Health Science Center; 2006.

10. Fritz F, Tilahun B, Dugas M. Success criteria for electronic medical record implementations in low-resource settings: a systematic review. J Am Med Inform Assoc 2015;22(2):479-88.

11. United Nations. Country classification: data sources, country classifications and aggregation methodology. In: United Nations, editor. World economic situation and prospects 2014. New York (NY): United Nations; 2014. p. 143-50.

12. World Health Organization. Medical records manual: a guide for developing countries. Manila, Philippines: World Health Organization; 2006.

13. Goldfarb NI. Assessing quality of primary care through medical record review: lessons and opportunities. Health Policy Newsl 2000;13(2):8.

14. Rodrigues J, Compte SS, De la Torre Diez I. E-Health systems: theory, advances and technical applications. London: ISTE Press; 2016.

15. Heart T, Ben-Assuli O, Shabtai I. A review of PHR, EMR and EHR integration: a more personalized healthcare and public health policy. Health Policy Technol 2017; 6(1):20-5. 
16. World Health Organization. Primary health care: now more than ever. Geneva, Switzerland: World Health Organization; 2008.

17. Mater W, Aldwairi M, Ibrahim R. Enhanced teamwork communication model for electronic clinical pathways in healthcare. Open Bioinform J 2018;11:140-63.

18. Henricks WH. "Meaningful use" of electronic health records and its relevance to laboratories and pathologists. J Pathol Inform 2011;2:7.

19. Evans RS. Electronic health records: then, now, and in the future. Yearb Med Inform 2016;Suppl 1:S48-61.

20. Ferrari R. Writing narrative style literature reviews. Med Writ 2015;24(4):230-5.

21. Afrizal S, Hakiem N, Sensuse DI. Analysis of the readiness of e-Government implementation at the ministerial level of the Republic of Indonesia. Proceedings of the International Conference on Business and Management Research (ICBMR 2017); 2017 Aug 15-16; Jakarta, Indonesia.

22. Timmings C, Khan S, Moore JE, Marquez C, Pyka K, Straus SE. Ready, set, change! Development and usability testing of an online readiness for change decision support tool for healthcare organizations. BMC Med Inform Decis Mak 2016;16:24.

23. Ajami S, Ketabi S, Isfahani SS, Heidari A. Readiness assessment of electronic health records implementation. Acta Inform Med 2011;19(4):224-7.

24. Lambooij MS, Drewes HW, Koster F. Use of electronic medical records and quality of patient data: different reaction patterns of doctors and nurses to the hospital organization. BMC Med Inform Decis Mak 2017;17(1):17.

25. Abdulrahman MD, Subramanian N. Barriers in implementing reverse logistics in Chinese manufacturing sectors: an empirical analysis. Proceedings of the POMS 23rd Annual Conference; 2011 Apr 20-23; Chicago, IL.

26. Mannan R, Murphy J, Jones M. Is primary care ready to embrace e-health? A qualitative study of staff in a London primary care trust. Inform Prim Care 2006;14(2): 121-31.

27. Shea CM, Reiter KL, Weaver MA, McIntyre M, Mose J, Thornhill J, et al. Stage 1 of the meaningful use incentive program for electronic health records: a study of readiness for change in ambulatory practice settings in one integrated delivery system. BMC Med Inform Decis Mak 2014;14:119.

28. Pandhi N, Yang WL, Karp Z, Young A, Beasley JW, Kraft S, Carayon P. Approaches and challenges to optimising primary care teams' electronic health record usage. In- form Prim Care 2014;21(3):142-51.

29. Mason P, Mayer R, Chien WW, Monestime JP. Overcoming barriers to implementing electronic health records in rural primary care clinics. Qual Rep 2017;22(11):294355.

30. Saleh S, Khodor R, Alameddine M, Baroud M. Readiness of healthcare providers for eHealth: the case from primary healthcare centers in Lebanon. BMC Health Serv Res 2016;16(1):644.

31. Shin P, Sharac J. Readiness for meaningful use of health information technology and patient centered medical home recognition survey results. Medicare Medicaid Res Rev 2013;3(4):mmrr.003.04.b01.

32. Melas CD, Zampetakis LA, Dimopoulou A, Moustakis VS. An empirical investigation of technology readiness among medical staff based in Greek hospitals. Eur J Inf Syst 2014;23(6):672-90.

33. Fuji KT, Galt KA, Serocca AB. Personal health record use by patients as perceived by ambulatory care physicians in Nebraska and South Dakota: a cross-sectional study. Perspect Health Inf Manag 2008;5:15.

34. Vydra TP, Cuaresma E, Kretovics M, Bose-Brill S. Diffusion and use of tethered personal health records in primary care. Perspect Health Inf Manag 2015;12:1c.

35. Ayatollahi H, Mirani N, Haghani H. Electronic health records: what are the most important barriers? Perspect Health Inf Manag 2014;11:1c.

36. Papoutsi C, Reed JE, Marston C, Lewis R, Majeed A, Bell D. Patient and public views about the security and privacy of Electronic Health Records (EHRs) in the UK: results from a mixed methods study. BMC Med Inform Decis Mak 2015;15:86.

37. Darko-Yawson S, Ellingsen G. Assessing and improving EHRs data quality through a socio-technical approach. Procedia Comput Sci 2016;98:243-50.

38. Terry AL, Thorpe CF, Giles G, Brown JB, Harris SB, Reid GJ, et al, Stewart M. Implementing electronic health records: Key factors in primary care. Can Fam Physician 2008;54(5):730-6.

39. Safdari R, Ghazisaeidi M, Jebraeily M. Electronic health records: critical success factors in implementation. Acta Inform Med 2015;23(2):102-4.

40. Kuo KM, Liu CF, Ma CC. An investigation of the effect of nurses' technology readiness on the acceptance of mobile electronic medical record systems. BMC Med Inform Decis Mak 2013;13:88.

41. Weiner BJ. A theory of organizational readiness for change. Implement Sci 2009;4:67. 
42. Sulmasy LS, Lopez AM, Horwitch CA; American College of Physicians Ethics, Professionalism and Human Rights Committee. Ethical implications of the electronic health record: in the service of the patient. J Gen Intern Med 2017;32(8):935-9. 